\title{
Predictors of Complications Secondary to Infective Endocarditis and Their Associated Outcomes: A Large Cohort Study from the National Emergency Database (2016-2018)
}

\author{
Tanveer Mir (1) - Mohammed Uddin · Waqas T. Qureshi · \\ Neelambuj Regmi · Imad M. Tleyjeh · Ghulam Saydain
}

Received: August 29, 2021 / Accepted: November 5, 2021 / Published online: November 24, 2021

(C) The Author(s) 2021

\begin{abstract}
Introduction: Literature regarding outcomes and predictors of complications secondary to infective endocarditis (IE) is limited. We aimed to study the outcomes and predictors of complications of IE.
\end{abstract}

Supplementary Information The online version contains supplementary material available at https:// doi.org/10.1007/s40121-021-00563-y.

T. Mir · M. Uddin

Internal Medicine, Detroit Medical Center Wayne State University, 4201, St Antoine St., Detroit, MI 48201, USA

\section{T. Mir $(\bowtie)$}

Internal Medicine, Baptist Health System, 300

Taylor Road,, Montgomery, AL 36117, USA

e-mail: gr6723@wayne.edu

W. T. Qureshi

Division of Cardiology, University of Massachusetts

School of Medicine, Worcester, MA, USA

\section{N. Regmi · G. Saydain}

Division of Pulmonary and Critical Medicine, Detroit Medical Center Wayne State University,

Detroit, MI, USA

I. M. Tleyjeh

Infectious Diseases Section, Department of Medical Specialties King Fahad Medical City, Riyadh, Saudi Arabia

I. M. Tleyjeh

Division of Epidemiology, Mayo Clinic College of

Medicine and Science, Rochester, MN, USA
Methods: Data from a national emergency department sample, which constitutes 20\% sample of hospital-owned emergency departments in the USA, were analyzed for hospital visits for IE. Complications of endocarditis were obtained by using ICD codes. Multivariable generalized linear method was used to evaluate predictors of in-hospital mortality and complications.

Results: Out of 255,838 adult IE patients (mean age $60.3 \pm 20.1$ years, $48.5 \%$ females), 97,803 (38.2\%) patients developed one or more major complications. The major complications were cardiovascular system complications $[57,900$ (22.6\%)], neurologic [42,851 (16.7\%)] complications, and renal $[16,236(6.4 \%)]$ complications. These included cardiogenic shock [3873 (1.5\%)], septic shock $[25,798(10.1 \%)]$, acute heart failure $[35,602(14 \%)]$, systemic thromboembolism (STE) [21,390 (8.36\%)], heart block $[11,430(4.47 \%)]$, in-hospital dialysis [2880 $(1.1 \%)]$, and disseminated intravascular coagulation (DIC) [2704 (1.1\%)]. Patients with complicated IE had risk of mortality (adjusted RR 1.12 , 95\% CI 1.11-1.13, $p<0.001)$. The complications strongly associated with mortality were septic shock (RR 1.29, 95\% CI 1.27-1.30, $p<0.001$ ), cardiogenic shock (RR $1.24,95 \%$ CI $1.20-1.29, p<0.001$ ), DIC (RR 1.4, 95\% CI $1.35-1.46, p<0.001$ ), and STE (RR 1.07, 95\% CI $1.05-1.08, p<0.001)$. Staphylococci were the predominant causative organisms (30.8\%) among the complicated IE subgroups with 
higher associated mortality (42.8\%). The main predictors of complications from IE were congenital heart disease, history of congestive heart failure, high Elixhauser comorbidity profile, staphylococcal infection, and fungal infections. The prevalence of cardiogenic shock increased over the study years from 1.13 to $1.98 \%$ ( $p$-trend 0.04).

Conclusion: Complicated IE is not uncommon and is associated with significant mortality. Staphylococcal infections were associated with high mortality rates. There has been an increasing trend of cardiogenic shock among IE patients across the US. Further research is needed to improve the outcomes of complicated endocarditis.

Keywords: Infective endocarditis; IE; Septic shock; Cardiogenic shock; Systemic thromboembolism; Mortality; Predictors; Disseminated intravascular coagulation (DIC)

\section{Key Summary Points}

Question: what was the impact of infective endocarditis in the US in 2016-2018?

Infective endocarditis (IE) was associated with significant complications including systemic thromboembolism (arterial embolism to the central nervous system and other systemic arterial embolisms), cardiogenic shock, disseminated intravascular coagulation (DIC), and acute heart failure

In-hospital mortality among IE patients was $6.52 \%$; however, the mortality was almost twice this rate in the complicated IE population

A significant number of patients had prosthetic valve or lead associated IE

The prevalence of cardiogenic shock increased over the study years from 1.13 in 2016 to $1.98 \%$ in 2018 (linear $p$ trend $0.04)$

\section{INTRODUCTION}

Infective endocarditis (IE) is associated with high morbidity and mortality [1-6]. The total number of disability-adjusted life years (DALYs) due to endocarditis has risen steadily since 1990, reaching 1.72 million (95\% UI: $1.36-1.94$ million) DALYs and 66,300 deaths (95\% UI: 46,200-75,900 deaths) in 2019 [7]. GBD 2019 estimated 1.09 million (95\% UI: 0.913-1.30 million) incident cases of endocarditis in 2019. A population-based study from Olmsted County reported an adjusted IE incidence of 5-7 cases per 100,000 person years in the US [1]. A retrospective study from the national inpatient sample for the years 2007-2011 reported increasing numbers of IE cases; however, the number of hospitalizations remained steady [2]. Mortality rates of up to $26 \%$ have been reported for IE $[1-5,8]$. Complications including acute heart failure, cardiogenic shock, and septic shock from IE can worsen the mortality with reported rates up to $52.5 \%$ [6].

To our knowledge, complications of IE including systemic thromboembolism (arterial embolism to the central nervous system and other systemic arterial embolisms), septic shock, and cardiogenic shock have not been studied on a large scale. Previous studies have reported age, varying degrees of heart block, acute kidney injury, and congestive heart failure as the major predictors for developing end-organ manifestations including cardiogenic shock in the IE patient population. However, the studies were done in small patient populations $[6,9]$.

Data regarding the predictors of mortality in patients with IE as well as trends, prevalence, and outcomes of major complications could provide information for improving healthcare policy making. Therefore, we aimed to examine national trends, predictors, and mortality of complications among patients diagnosed with IE for the years 2016-2018 from the national emergency department sample database. 


\section{METHODS}

\section{Study Population and Inclusion Criteria}

This is an observational cohort study of patients hospitalized for IE during the years 2016-2018 in the National Emergency Department Sample (NEDS) database. The NEDS constitutes an approximately $20 \%$ sample of hospital-owned emergency departments (ED) in the US [10]. Using a stratified, random sampling design, a sample of hospital-owned emergency departments from the US participating in both the State Inpatient Databases (SID) and the State Emergency Department Databases (SEDD) was selected, and $100 \%$ of the emergency departments visits from the selected hospital-owned emergency departments were retained. Hospitals were included in the NEDS sample based on geographic region (northeast, mid-west, west, or south), location (urban or rural), teaching status (teaching or non-teaching), ownership (public, private not for profit, private for profit), and trauma center designation. A total of 950 emergency departments were included in the national emergency department database. From each selected emergency department, all visits were included, which amounted to $>33$ million unweighted visits each year. Patients with age $<18$ years at the time of presentation were excluded from the study. A similar methodologic approach was used to our previous studies $[11,12]$.

\section{Study Definitions}

Infective endocarditis was defined by International Classification of Diseases-10 (ICD-10) codes of "I33.0", "A39.51", “A52.03", "B37.6", "I33.9", "I39", "I38" and "A54.83". Patients younger than 18 years $(n=4978)$ were excluded. Details of ICD codes utilized to identify various complications are given in in the supplementary material. Complications were subdivided into neurologic (meningoencephalitis, seizures, meningitis, brain abscess, and stroke), cardiovascular (including cardiac arrest, cardiogenic shock, acute myocardial infarction, acute heart failure, heart block), renal [acute kidney injury requiring dialysis, acute tubular necrosis (ATN)], disseminated intravascular coagulation (DIC), and septic shock. We classified endocarditis into native valve, prosthetic valve, and lead associated IE as per previous history of procedures. This method has been validated previously and published in the literature [13].

\section{Patient and Hospital Characteristics}

Baseline patient demographic characteristics (age, sex, insurance payer) were extracted. ICD10 diagnostic codes were used to identify hypertension, diabetes mellitus, hyperlipidemia, obesity, smoking, congestive heart failure, peripheral vascular disease (PVD), chronic kidney disease (CKD), fluid electrolyte imbalance, liver disease, chronic obstructive pulmonary disease (COPD), history of cardiac valve surgery, history of cardiac assist or lead device procedure, history of permanent pacemaker implantation, congenital heart disease, HIVAIDS, drug abuse, malignancy, and intravenous drug use. Elixhauser comorbidity index codes were also used to extract comorbidities [14]. All open surgical procedures open or percutaneous, aortic, mitral, tricuspid, pulmonary valve, intraventricular, and periventricular procedures were extracted using ICD-10 procedural classification system (PCS) codes (Supplementary material).

\section{Outcomes}

The primary outcome of the study was in-hospital mortality. We also evaluated cause-specific mortality and trends of mortality from IE complicated by septic shock, cardiogenic shock, systemic thromboembolism (ICD codes provided in supplementary material), acute heart failure, DIC, acute kidney injury requiring hemodialysis during hospitalization, and prevalence of IE over the study years 2016-2018.

\section{Statistical Methods}

Categorical variables were expressed as weighted values along with percentages, and 
continuous variables were expressed as mean \pm standard deviation if the variable was not skewed and as median with 25th and 75th percentiles otherwise. Descriptive statistics were performed for demographics and comorbidities, which were stratified by the septic shock, cardiogenic shock, and systemic thromboembolism and were compared with the rest of the population. We used survey procedure "svy" to perform weighted analysis. Pearson's chi-square test was used to compare categorical variables, and linear regression was used to compare continuous variables. A similar methodologic approach was used as in our previous studies $[11,12]$.

We classified endocarditis in native valve, prosthetic valve and lead associated IE as per previous history of such procedures using ICD codes, and proportions were compared using chi-square test. Complications of IE were divided into body systems: (1) central nervous system including systemic embolism, meningoencephalitis, seizures, meningitis, and brain abscess; (2) cardiovascular system including cardiac arrest, cardiogenic shock, acute myocardial infarction, acute heart failure, and heart block; (3) renal including acute kidney injury requiring dialysis and acute tubular necrosis; (4) hematologic system including disseminated intravascular coagulation (DIC); (5) septic shock. We then calculated mortality associated with each complication. Mortality associated with each type of IE was also computed. Effect of surgical valve procedures on mortality was calculated for each complication. The proportions were compared using chisquare test.

We computed the relative risk (RR) with 95\% confidence interval (CI) for the association of mortality with each complication in multivariable generalized linear regression model 1 adjusted for variables hypertension, diabetes mellitus, hyperlipidemia, obesity, smoking, congestive heart failure, peripheral vascular disease (PVD), chronic kidney injury, liver disease, chronic obstructive pulmonary disease, history of cardiac valve surgery, history of cardiac assist or lead device procedure, history of permanent pacemaker implantation, congenital heart disease, HIV-AIDS, cancer, and intravenous drug abuse. We also calculated the attributable risk for the mortality associated with the complications of the IE patient population.

We used a similar model to evaluate the association of these covariates with development of any complication of IE in a multivariable generalized linear regression model.

We also assessed the yearly trends in mortality, number of hospital visits for IE, and complicated IE and examined their linear trends. We also assessed trends of individual complications as well. All analyses were weighted. Statistical analysis was performed using STATA version 16.1 (College Station, TX, USA). All $p$ values were two sided, with a significance level of $p<0.05$.

Length of stay was calculated for alive patients. A multivariable-adjusted Poisson regression for model, including age, systemic thromboembolism, cardiogenic shock, septic shock, female gender, pulmonary embolism, acute kidney injury, disseminated intravascular coagulation, meningitis, meningoencephalitis, acute encephalopathy, and inpatient hemodialysis, was used to calculate incidence rate ratio (IRR) and 95\% confidence interval for association with length of stay.

\section{RESULTS}

A total of 255,838 adult IE patients (mean age $60.2 \pm 20.0$ years, $48.5 \%$ females) were recorded in the NEDS for the years 2016-2018 after exclusion of the pediatric population (Fig. 1). Of these, a significant number of patients $[97,803$ $(38.2 \%)]$ had one or more complications from IE. Native valve endocarditis occurred in $213,850(83.6 \%)$ patients and prosthetic valve in $18,889(7.4 \%)$, and implantable device-related IE occurred in 23,099 $(9.0 \%)$ patients. Baseline characteristics are provided in Table 1. Patients with complicated endocarditis were more likely to be elderly males with high prevalence of diabetes mellitus, hypertension, renal failure, liver diseases, peripheral vascular disease, hyperlipidemia, chronic obstructive pulmonary disease, and congestive heart failure. Baseline characteristics of major complications 


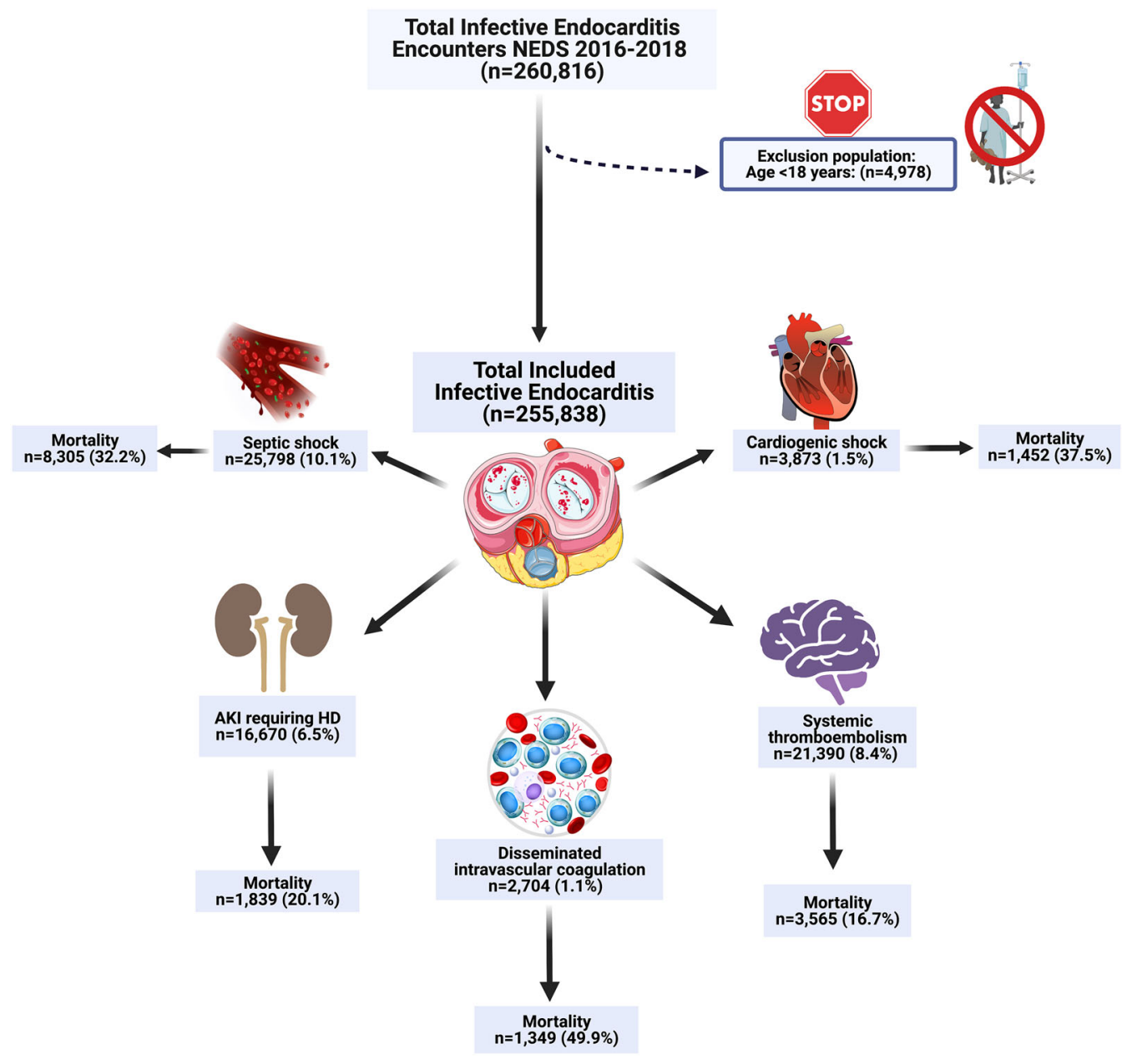

Fig. 1 Graphical representation of infective endocarditis-related patient encounters and clinical outcomes associated with these encounters during the hospitalization. $A K I$ acute kidney injury, $H D$ hemodialysis (created with biorender.com)

are provided in supplementary table 1 . Among the etiologies, staphylococcal infection complicated $38,075(35.6 \%)$ vs. 24,662 (16.6\%) noncomplicated IE, streptococcal infection 12,258 $(11.5 \%)$ vs. $9951(6.7 \%)$ non-complicated IE, and fungal in $1122(1.15 \%)$ vs. 801 (0.5\%) noncomplicated IE patients. All results were statistically significant $(p=0.001)$.

The total number of patients who had rheumatic heart disease (RHD) among IE patients was $21,048(8.23 \%)$. There was a significant difference in mortality rate $(p=0.0003)$ among the RHD subgroup: 1640 (7.79\%) vs. $15,030(6.4 \%)$ for the non-RHD group. A total of 5895 (2.3\%) had congenital heart disease (CHD) among the IE patient population. The mortality rate among patients with IE with CHD 373 (6.33\%) compared to 16,297 (6.52\%) in nonCHD was not statistically significant $(p=0.7)$.

\section{Complications of IE}

Cardiovascular complications occurred among 57,900 (22.6\%), neurologic complications among $42,851(16.7 \%)$, renal complications among 16,236 (6.4\%), hematologic complications (DIC) among $2704(1.1 \%)$, and septic shock among 25,798 (10.1\%) patients. Cardiovascular complications were the most frequent ones and included cardiogenic shock [3873 $(1.5 \%)]$, acute heart failure [35,602 (14\%)], acute myocardial infarction $[14,879$ (5.8\%)], 
Table 1 Baseline characteristics of patients with and without complicated IE

\begin{tabular}{|c|c|c|c|}
\hline \multirow[t]{2}{*}{ Variables } & \multicolumn{2}{|l|}{ Infective endocarditis } & \multirow[t]{2}{*}{$p$-value } \\
\hline & With complications $(n=97,799)$ & Without complications $(n=157,988)$ & \\
\hline Age & $64.1 \pm 18.6$ & $58.2 \pm 20.6$ & $<0.001$ \\
\hline Female & $44,089(45.1 \%)$ & $79,903(50.6 \%)$ & $<0.001$ \\
\hline Male & $53,710(54.9 \%)$ & $78,084(49.4 \%)$ & $<0.001$ \\
\hline Medicare & $59,291(62 \%)$ & $77,677(50.7 \%)$ & $<0.001$ \\
\hline Medicaid & $18,306(19.1 \%)$ & $37,748(24.7 \%)$ & $<0.001$ \\
\hline Private insurance & $13,502(14.1 \%)$ & $26,074(17 \%)$ & $<0.001$ \\
\hline Self-pay & $4379(4.6 \%)$ & $11,390(7.4 \%)$ & $<0.001$ \\
\hline Teaching Hospital & $66,309(67.8 \%)$ & $94,667(59.9 \%)$ & $<0.001$ \\
\hline Urban Hospital & $93,114(95.2 \%)$ & $145,847(92.3 \%)$ & $<0.001$ \\
\hline Hypertension & $68,046(69.6 \%)$ & $88,433(56 \%)$ & $<0.001$ \\
\hline Hyperlipidemia & $33,667(34.4 \%)$ & $39,624(25.1 \%)$ & $<0.001$ \\
\hline Diabetes miletus & $33,264(34 \%)$ & $38,219(24.2 \%)$ & $<0.001$ \\
\hline Obesity & $13,211(13.5 \%)$ & $13,766(8.7 \%)$ & $<0.001$ \\
\hline Weight loss & $18,618(19 \%)$ & $13,012(8.2 \%)$ & $<0.001$ \\
\hline Smoker & $18,970(19.4 \%)$ & $42,202(26.7 \%)$ & $<0.001$ \\
\hline Drug abuse & $16,597(17 \%)$ & $34,211(21.6 \%)$ & $<0.001$ \\
\hline Intravenous drug use & $10,837(11.1 \%)$ & $23,101(14.6 \%)$ & $<0.001$ \\
\hline Prior stroke & $8574(8.8 \%)$ & $11,820(7.5 \%)$ & $<0.001$ \\
\hline Congestive heart failure & $56,118(57.4 \%)$ & $36,184(22.9 \%)$ & $<0.001$ \\
\hline Congenital heart disease & $3022(3.1 \%)$ & $2872(1.8 \%)$ & $<0.001$ \\
\hline History of lead & $6413(6.6 \%)$ & $8393(5.3 \%)$ & $<0.001$ \\
\hline History of assist device & $4166(4.3 \%)$ & $4126(2.6 \%)$ & $<0.001$ \\
\hline History of prosthetic valve & $15,957(16.3 \%)$ & $22,111(14 \%)$ & $<0.001$ \\
\hline Peripheral vascular disease & $13,247(13.5 \%)$ & $13,039(8.2 \%)$ & $<0.001$ \\
\hline Chronic pulmonary disease & $25,458(26 \%)$ & $13.5(38.2 \%)$ & $<0.001$ \\
\hline Liver disease & $14,120(14.4 \%)$ & $15,043(9.5 \%)$ & $<0.001$ \\
\hline Renal failure & $36,730(37.6 \%)$ & $30,531(19.3 \%)$ & $<0.001$ \\
\hline Hemodialysis & $13,365(13.7 \%)$ & $12,010(7.6 \%)$ & $<0.001$ \\
\hline HIV/AIDS & $880(0.9 \%)$ & $1608(1 \%)$ & 0.1870 \\
\hline Cancer & $5504(5.6 \%)$ & $6636(4.2 \%)$ & $<0.001$ \\
\hline
\end{tabular}


Table 2 Mortality from major complications. RR with 95\% CI in multivariable generalized linear model for association with mortality

\begin{tabular}{|c|c|c|c|c|}
\hline Complications & $\begin{array}{l}\text { Total } n=255,838(\% o f \\
\text { total IE) }\end{array}$ & $\begin{array}{l}\text { Mortality } n=16,670 \text { (\% of total } \\
\text { died) }\end{array}$ & $\mathbf{R R}(\mathrm{CI})$ & $p$-value \\
\hline $\begin{array}{l}\text { Systemic } \\
\text { thromboembolism }\end{array}$ & $21,390(8.4 \%)$ & $3565(21.4 \%)$ & $\begin{array}{c}1.07(1.06, \\
1.09)\end{array}$ & $<0.001$ \\
\hline Seizures & $2981(1.2 \%)$ & $347(2.1 \%)$ & $1.03(1,1.05)$ & 0.012 \\
\hline Acute encephalopathy & $25,987(10.2 \%)$ & $5608(33.6 \%)$ & $\begin{array}{l}1.15(1.14 \\
1.17)\end{array}$ & $<0.001$ \\
\hline Meningitis & $576(0.2 \%)$ & $116(0.7 \%)$ & $\begin{array}{c}1.07(0.99 \\
1.15)\end{array}$ & 0.053 \\
\hline Meningoencephalitis & $41(0.02 \%)$ & $14(0.1 \%)$ & $\begin{array}{c}1.37(0.95 \\
1.97)\end{array}$ & 0.085 \\
\hline Brain abscess & $749(0.3 \%)$ & $102(0.6 \%)$ & $\begin{array}{c}1.02(0.97 \\
1.08)\end{array}$ & 0.358 \\
\hline Acute tubular necrosis & $13,005(5.1 \%)$ & $3407(20.4 \%)$ & $\begin{array}{l}1.18(1.16 \\
1.20)\end{array}$ & $<0.001$ \\
\hline $\begin{array}{r}\text { AKI requiring } \\
\text { hemodialysis }\end{array}$ & $16,670(6.5 \%)$ & $1839(11 \%)$ & $\begin{array}{l}1.13(1.09 \\
1.17)\end{array}$ & $<0.001$ \\
\hline DIC & $2704(1.1 \%)$ & $1349(8.1 \%)$ & $\begin{array}{l}1.45(1.40, \\
1.51)\end{array}$ & $<0.001$ \\
\hline Cardiac arrest & $4928(2 \%)$ & $3188(19.1 \%)$ & $\begin{array}{c}1.73(1.68, \\
1.79)\end{array}$ & $<0.001$ \\
\hline Cardiogenic shock & $3873(1.5 \%)$ & $1452(8.7 \%)$ & $\begin{array}{l}1.27(1.22 \\
1.31)\end{array}$ & $<0.001$ \\
\hline Acute heart failure & $35,602(13.9 \%)$ & $3964(23.8 \%)$ & $\begin{array}{l}1.02(1.01, \\
1.03)\end{array}$ & $<0.001$ \\
\hline $\begin{array}{l}\text { Acute myocardial } \\
\text { infarction }\end{array}$ & $14,879(5.8 \%)$ & $3180(19.1 \%)$ & $\begin{array}{c}1.11(1.10, \\
1.13)\end{array}$ & $<0.001$ \\
\hline $\begin{array}{l}\text { Cardiac conduction } \\
\text { block }\end{array}$ & $11,430(4,5 \%)$ & $1133(6.8 \%)$ & $0.99(0.99,1)$ & 0.523 \\
\hline Septic shock & $25,798(10.1 \%)$ & $8305(32.8 \%)$ & $\begin{array}{c}1.32(1.30 \\
1.34)\end{array}$ & $<0.001$ \\
\hline $\begin{array}{l}\text { Staphylococcus } \\
\text { infection }\end{array}$ & $30,124(30.8 \%)$ & $6282(42.4 \%)$ & $\begin{array}{l}1.06(1.05 \\
1.07)\end{array}$ & $<0.001$ \\
\hline Fungal infection & $1122(1.1 \%)$ & $250(1.7 \%)$ & $\begin{array}{c}1.07(1.03 \\
1.10)\end{array}$ & $<0.001$ \\
\hline Streptococcus infection & $10,226(10.5 \%)$ & $1261(8.5 \%)$ & $1.01(1,1.02)$ & 0.021 \\
\hline
\end{tabular}

$I E$ infective endocarditis, $D I C$ disseminated intravascular coagulation, $A K I$ acute kidney injury 
and heart block of any degree [11,430 (4.47\%)]. Systemic thromboembolism was recorded for $21,390(8.36 \%)$ patients among which 19,976 (7.8\% of IE patients) had stroke. Individual complications with their associated mortality are given in Table 2 .

\section{Inpatient Procedures}

Total surgical procedures were performed in $11,600(4.6 \%)$ of IE patients. Of these procedures, 8729 (9\%) were done among complicated IE and 2871 (1.8\%) were done among noncomplicated IE patients. Among the surgical procedures, aortic valve surgery was done in $4783(1.87 \%)$, mitral valve in 4189 (1.64\%), tricuspid in $2352(0.9 \%)$, and pulmonary valve surgery in $63(0.02 \%)$, and $2305(1 \%)$ were nonspecific procedures performed in IE patients.

\section{Mortality}

Out of 255,838 IE patients, 16,670 (6.52\%) died during the hospitalization. Higher mortality was observed among complicated IE patients $[14,818(15.2 \%)]$. On subgroup analysis of the mortality associated with complications from IE, higher rates of mortality were associated with septic shock [8305 (32.2\%)], cardiogenic shock [1452 (37.5\%)], cardiac arrest [3188 $(64.7 \%)]$, acute heart failure [3964 (11.1\%)], acute myocardial infarction [3180 (21.4\%)], cardiac conduction block [1133 (10\%)], acute encephalopathy [5608 (21.6\%)], meningitis [116 (20.2\%)], systemic thromboembolism $3565(16.7 \%)$, acute kidney injury requiring dialysis [1839 (20.1\%)], acute tubular necrosis [3407 (26.2\%)], and DIC [1349 (49.9\%)] (Table 2). The population attributable risk of mortality from complications was $84 \%$ $(p<0.001)$. The mortality associated with each complication in the surgical vs. the non-surgical groups is presented in Table 3.

Table 3 Surgical valve procedures and the effects on mortality among different complications

\begin{tabular}{lllc}
\hline Variables & Mortality & & $\boldsymbol{P}$-value \\
\cline { 2 - 4 } & With surgery & Without surgery & \\
\hline Systemic thromboembolism & $149(7.4 \%)$ & $3417(17.6 \%)$ & $<0.0001$ \\
Disseminated intravascular coagulation & $166(40.2 \%)$ & $1184(51.7 \%)$ & 0.05 \\
Septic shock & $620(25.4 \%)$ & $7685(32.9 \%)$ & 0.003 \\
Seizures & $16(10.9 \%)$ & $331(11.7 \%)$ & 0.9 \\
Brain abscess & $4(3.6 \%)$ & $98(15.5 \%)$ & 0.001 \\
Acute encephalopathy & $381(21.4 \%)$ & $5227(21.6 \%)$ & 0.9 \\
Acute heart failure & $420(6 \%)$ & $3544(11 \%)$ & 0.4 \\
Acute myocardial infarction & $298(19.3 \%)$ & $2882(21.6 \%)$ & 0.3 \\
Cardiogenic shock & $329(21.4 \%)$ & $1123(48 \%)$ & $<0.0001$ \\
Cardiac arrest & $259(45.2 \%)$ & $2928(67.3 \%)$ & $<0.0001$ \\
Cardiac conduction block & $326(11.9 \%)$ & $808(9.3 \%)$ & 0.05 \\
Acute tubular necrosis & $439(23.9 \%)$ & $2969(26.6 \%)$ & 0.2 \\
Acute kidney injury & $797(14.9 \%)$ & $9400(15.7 \%)$ & 0.5 \\
AKI requiring hemodialysis & $32(13.8 \%)$ & $857(32.4 \%)$ & 0.0009 \\
\hline
\end{tabular}

$A K I$ acute kidney injury 


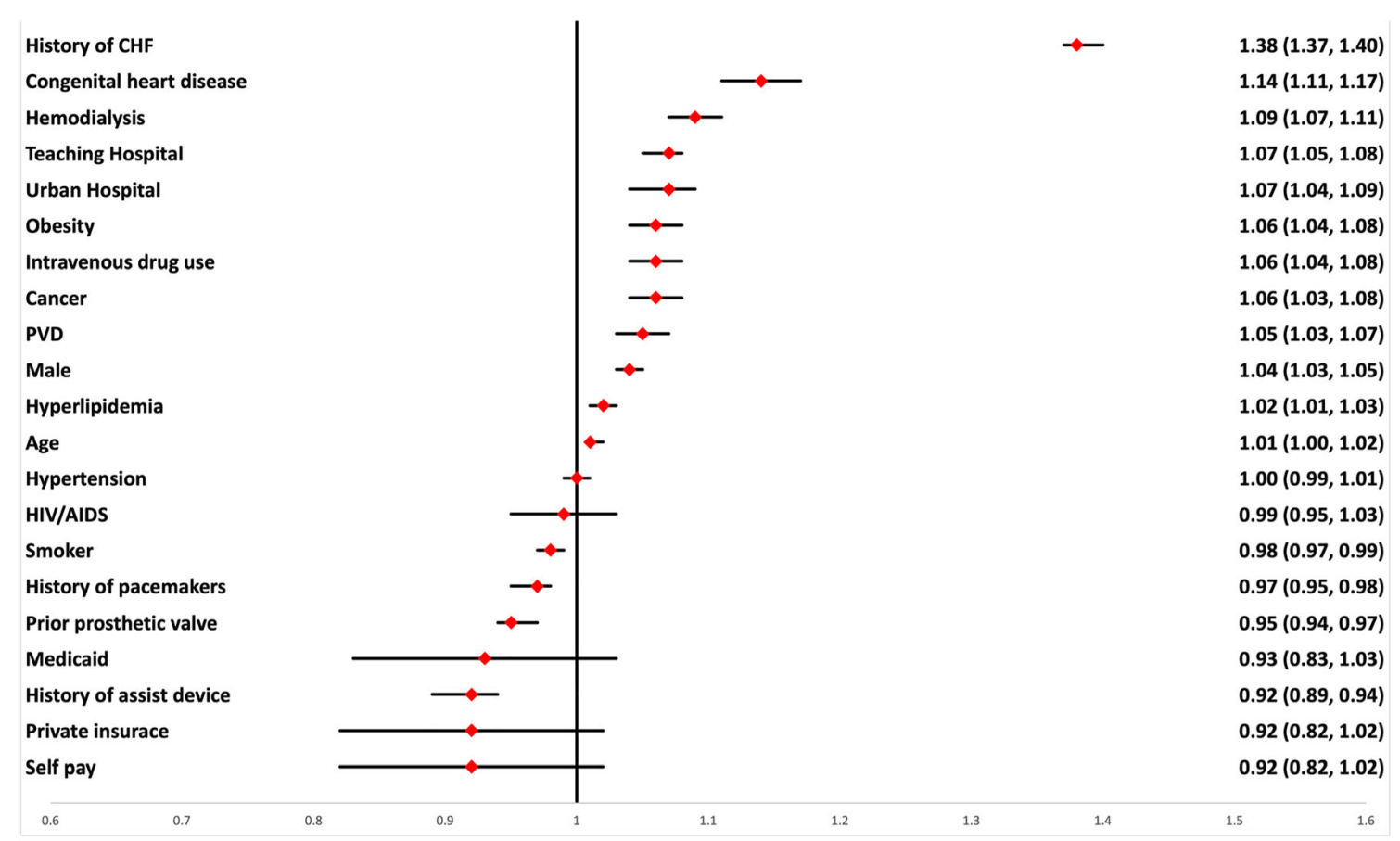

Fig. 2 Predictors of complicated IE. Relative risk and 95\% confidence interval for different predictors. PVD peripheral vascular disease, $C H F$ congestive heart failure

In a multivariable generalized linear model adjusted for model 1 variables, septic shock (RR $1.29,95 \%$ CI $1.27-1.30, p<0.001)$, cardiogenic shock (RR 1.24, 95\% CI 1.20-1.29, $p<0.001$ ), and DIC (RR 1.4, 95\% CI 1.35-1.46, $p<0.001$ ) were strongly associated with mortality. The detailed analysis is given in Table 2 .

\section{Predictors of Complicated Infective Endocarditis}

In a multivariable generalized linear model adjusted for model 1 variables, male gender (RR $1.04,95 \%$ CI 1.03-1.05, $p<0.001)$, congestive heart failure (RR 1.38, 95\% CI 1.37-1.40, $p<0.001$ ), and congenital heart disease (RR $1.14,95 \%$ CI 1.11-1.17, $p<0.001$ ) were predominantly associated with complications among IE while history of prosthetic valve (RR $0.95,95 \%$ CI $0.94-0.97, p<0.001$ ), history of assist devices (RR 0.92, 95\% CI 0.89-0.94, $p<0.001)$, history of permanent pacemaker implantation valve (RR 0.97, 95\% CI 0.95-0.98, $p<0.001$ ), and smoking (RR 0.98, 95\% CI $0.97-0.99, p<0.001)$ were less likely associated with complicated IE. All predictors are given in Fig. 2.

\section{Trends}

There were no statistically significant temporal trends of mortality (linear $p$ trend 0.16), septic shock (linear $p$ trend 0.16), systemic thromboembolism (linear $p$ trend 0.13), prevalence of IE (linear $p$ trend 0.29), prevalence of complicated IE (linear $p$ trend $>0.05$ ), and acute heart failure among IE (linear $p$ trend $>0.05$ ) over the study years. The prevalence of cardiogenic shock increased over the study years from 1.13 to $1.98 \%$ (linear $p$ trend 0.04 ) (Fig. 3).

\section{Length of stay}

The length of stay was longer among patients with cardiogenic shock, with a median of 16 days $(9,29)$ compared to patients with septic shock, 13 days $(7,24)$, and systemic thromboembolism 13 days $(7,22)$. Systemic thromboembolism (IRR 1.25, $p<0.001$ ), cardiogenic 


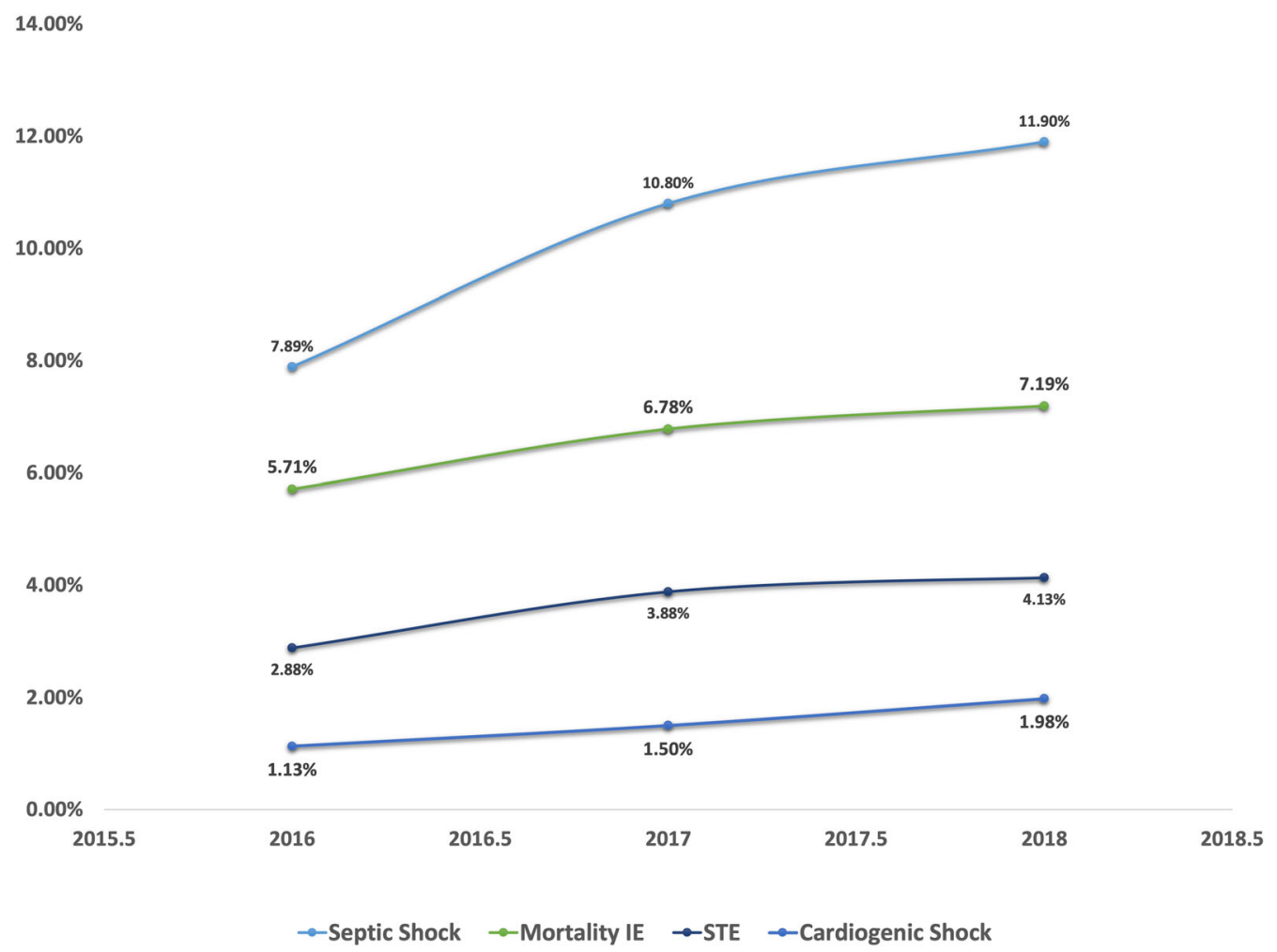

Fig. 3 Trends of mortality in IE, septic shock prevalence, cardiogenic shock prevalence, disseminated intravascular coagulation (DIC), acute heart failure (AHF), and systemic thromboembolism prevalence over the study years

shock (IRR 1.25, $p<0.001$ ), septic shock (IRR $1.28, p<0.001$ ), acute tubular necrosis (IRR $1.50, p<0.001$ ), brain abscess (IRR 1.41, $p<0.001$ ), meningoencephalitis (IRR 1.5, $p<0.01$ ), acute heart failure (IRR 1.13, $p<0.001)$, acute kidney injury requiring dialysis (IRR 1.15, $p<0.001$ ), and disseminated intravascular coagulation (IRR 1.01, $p<0.001$ ) were associated with increased length of stay and acute myocardial infarction (IRR 0.98, $p<0.001)$ was less likely associated with length of stay (Fig. 4).

\section{DISCUSSION}

To the best of our knowledge, this is the first and largest study that has evaluated comprehensively the various complications of IE in a contemporary national level dataset. The mortality rates from IE have been reported to be up
2016-2018. Linear $p$-trend was significant for cardiogenic shock ( $p$-trend 0.04). IE infective endocarditis, STE systemic thromboembolism

to $26 \%[1-3,8]$. The overall mortality among patients with IE in our analysis was $6.5 \%$. Higher mortality rates (15.2\%) were observed among complicated IE patients. Up to $84 \%$ of this mortality was attributable to complications of IE. Complications associated with IE have been reported to worsen survival outcomes [6, 15-17]. Despite the improvement in the healthcare system and management of IE, we observed a significant proportion of IE patients with one or more complications. We observed that $84 \%$ of mortality in the IE population was attributable to these complications when population attributable risk was calculated. Staphylococcal infections continued to predominate among the etiologies of IE. Higher rates of staphylococcal infections were more commonly seen in patients with complicated IE than in non-complicated IE patients. A prospective study of 1779 patients with IE 


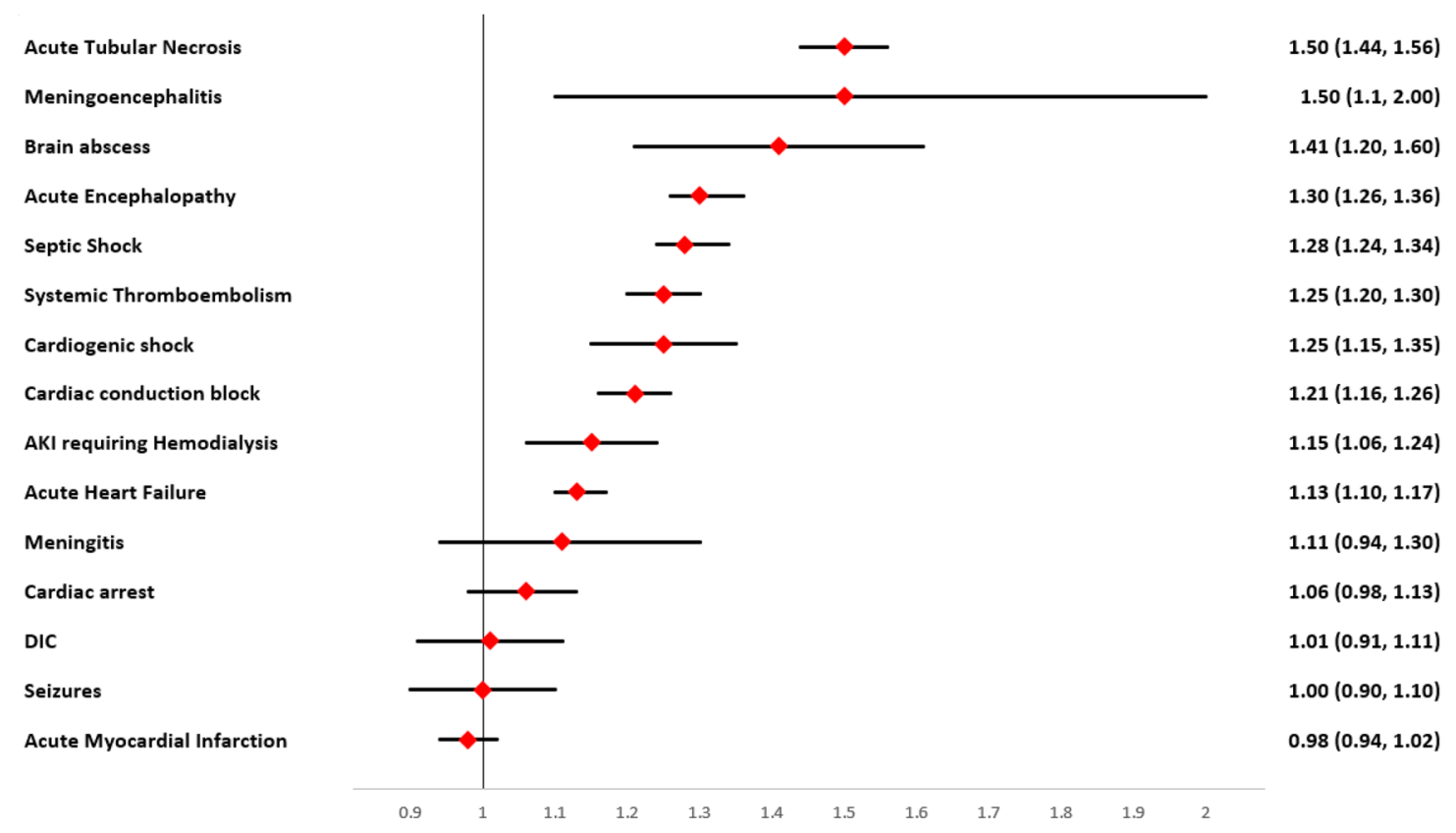

Fig. 4 Predictors of length of hospital stay in patients with infective endocarditis. Incidence rate ratio and $95 \%$ confidence interval for different predictors. $A K I$ acute kidney injury, $D I C$ disseminated intravascular coagulation

reported a higher prevalence of staphylococcal infection with worse outcomes [18]. Another prospective study of 6235 patients with confirmed IE showed that Staphylococcus aureus, Pseudomonas aeruginosa, and Candida infection are associated with higher in-hospital mortality [19].

Surgical valve procedures improved mortality among complicated IE patients, as has been previously reported $[20,21]$. Since valve damage from IE or high disease burden can worsen the outcome, surgical valve replacement or valve repair would improve mortality [22]. This could be the reason for improved mortality among the subgroup of complicated IE patients who had surgical valve procedures in our patient population. The observed rates of surgical procedures are similar to what has been reported from a retrospective study from the national inpatient sample for the years $2000-2016$ [13, 23]. This suggests improvement in rates of surgical procedures especially for patients with complicated IE. Intravenous drug use was strongly associated with complicated IE, and it was an independent predictor of mortality and new episodes of endocarditis, as has been reported previously $[13,24]$.
Interestingly, previous history of prosthetic valve surgery or implanted leads/pacemakers was less likely associated with mortality among IE patients. A multicenter European study on 384 patients revealed no statistical association of mortality among IE patients with prosthetic valves [25]. One important reason for this could be that such patients seek medical care sooner and hence get earlier treatment, which has been shown to improve complications and mortality [26]. However, previous studies have reported a higher association of mortality with prosthetic valve endocarditis and double valve infection [6, 24].

On multivariable generalized linear regression analysis, male gender, history of congestive heart failure, congenital heart disease, and cardiovascular comorbidities were associated with complicated IE. Congestive heart failure had a strong association with mortality from IE, as has been reported previously $[20,27]$.

\section{Cardiovascular System}

Most of the complications from IE were related to the cardiovascular system with significant 
impact on mortality. Patients with cardiogenic shock had a high mortality rate, and cardiogenic shock was a strong predictor of mortality from IE. The average mortality for patients who had cardiogenic shock among IE cases was $37.5 \%$. We observed a prevalence of $1.5 \%$ cardiogenic shock in our patient population. A prospective study of 4856 IE patients reported a rate of $5 \%$ cardiogenic shock with mortality rates of $52.5 \%$ [6]. The high mortality rate could be because these patients were sicker as a significant number of the cardiogenic shock patients $(54.7 \%)$ required mechanical ventilation during hospitalization. Also, higher rates of systemic thromboembolism (12.4\%) were noted in the subgroup, as was the case with septic shock, which could have worsened the mortality.

Interestingly, $6.5 \%$ of patients with IE had acute myocardial infarction events recorded during the hospitalization. Previously, multiple cases have reported acute myocardial infarction in IE [28-30]. One in every five patients with acute myocardial infarction with IE died, which is concerning and suggests early dialysis and intervention to improve mortality. The main cardiovascular predictors of complications among the IE patient population were history of congestive heart failure and congenital heart disease. In a prospective cohort of 3116 adult patients, congestive heart failure was an independent predictor of mortality [31]. Acute heart failure exacerbation was recorded among 13.9\% IE patients, of which $11 \%$ died. The mortality rates reported for IE with heart failure are up to $40 \%$ [32]. The mortality results in our study could be low because we separated cardiogenic shock patients from the acute heart failure population.

In our present analysis, $2.3 \%$ of IE patients had CHD; however, the mortality rate among CHD and non-CHD patients was not statistically significant $(6.33 \%$ vs. $6.52 \% ; p=0.7)$. A retrospective study of 144 patients with CHD and IE showed a mortality rate of $6.9 \%$ [33]. We also observed $8.23 \%$ RHD related to IE, and the mortality rate was significant $(p=0.0003)$ in the RHD and non-RHD group (7.79\% vs. 6.4\%). Another cardiac complication was conduction block, which was associated with higher mortality. Every 20th patient had a cardiac conduction block, which worsened mortality. Previous studies have described a rate of up to $30 \%$ conduction block in IE [34]. Lastly, cardiac arrest complicated a significant number of patients with IE, and mortality rates of $64.7 \%$ were observed, as has been reported previously [35]. More research is required to improve the mortality rates.

\section{Septic Shock}

Septic shock was a significant complication associated with IE. A prospective study of 4856 patients evaluating IE reported a mortality rate of $52.5 \%$ with septic shock in IE [6]. Patients in whom IE was complicated by septic shock had mortality rates of $32.3 \%$, and septic shock was a strong predictor of mortality from IE. Previous study comprising 294 patients with definite IE admitted between 2000 and 2011 showed that presence of septic shock among IE was associated with worsening in-hospital mortality (OR $35.969, P<0.001)$ [36]. The higher mortality in the subgroup could be multifactorial. These patients are likely sicker with organ failure, which could worsen mortality. A significant number of patients among septic shock patients (47.7\%) needed mechanical ventilation during hospitalization. Second, we observed higher rates of systemic thromboembolism in this subgroup (11.8\%). Systemic thromboembolism was associated with higher mortality among IE patients with and without septic shock. This could be another reason for higher mortality in patients with septic shock with IE. The overall rate of systemic thromboembolism in patients with IE was $4.9 \%$. Previous studies have reported $13-49 \%$ rates of systemic thromboembolism in patients with IE [37]. Early diagnosis and management can improve the rates of systemic thromboembolism. A prospective study of 1437 patients reported improvement in embolic stroke rates with antibiotic management [38]. Disseminated intravascular coagulation was recorded among $1.1 \%$ of the patient population, and half of them died. Patients with DIC are mostly very sick, and this could explain the high mortality among this subgroup [39]. 
Our present analysis showed mortality benefits with and without surgery associated with IE complicated by septic shock. This is supported by previous analysis showing surgical treatment had a positive impact on mortality in patients with septic shock and IE (OR 5.157, $P<0.001$ ) as well as on 1-year survival (hazard ratio 3.092, $P<0.001$ ) [36]. This may suggest that improved mortality rates can be achieved through surgical treatments in patients with septic shock and IE.

\section{Central Nervous System Complications}

A significant number of patients had neurologic complications including meningitis, acute encephalopathy, meningoencephalitis, seizures, and brain abscess among the IE patients. There was significant impact of all these complications on mortality and increased length of stay leading to increased healthcare burden. In a prospective cohort of 3116 adult patients with cerebral complications, abscess was an independent predictor of mortality in the IE population [31]. Our analysis showed that acute encephalopathy was among the ones with highest mortality associated with IE. Neurologic complications occurred in $16.7 \%$ of our patient population with mortality rates of $18 \%$. Previous studies have mentioned neurologic complication rates of $25-70 \%$ with mortality rates up to $30 \%[15,16]$. Early antibiotic use has been reported to improve the rates of neurologic complications and associated mortality $[16,40]$.

\section{Renal Complications}

A significant number of patients had acute tubular necrosis and kidney injury requiring dialysis. As per reports from the European Society of Cardiology, acute kidney injury can occur in $6-30 \%$ of IE patients [41]. Acute kidney injury was associated with higher mortality, as has been reported previously [42]. Acute kidney injury complicated $25.5 \%$ of patients, and $1.1 \%$ required dialysis during the hospitalization. Early diagnosis and management can improve the rates of acute kidney injury and related complications.
The trends for septic shock, systemic thromboembolism, acute heart failure, acute myocardial infarction, disseminated intravascular coagulation, and mortality from IE were steady over the study years, 2016-2018. However, there were increasing temporal trends in the prevalence of cardiogenic shock in IE patients over the study years. Despite improvements in healthcare and use of advanced antibiotics, the trend of complications from IE has not improved over the years, which is concerning. Early diagnosis and antibiotic treatment can improve the rates of complications from IE, as has been reported previously [26]. The trend of IE has been steady over the study years, as has been reported previously $[43,44]$. However, a retrospective study from the National Inpatient Sample for 2000-2011 reported an increasing trend of IE [45].

All the major complications were associated with prolonged hospital stay among alive patients. Relatively higher median length of stay was noticed for patients who had cardiogenic shock and a significant number of patients had disposition to hospice among the patients with complicated IE.

Our study has several limitations. First, this is a retrospective observational study, and inference regarding causation should be made with caution as controlling for comorbidities is challenging. Also, we relied on reported ICD-10 codes to identify diagnoses to perform our analysis. The national emergency database is an administrative database that could be subject to inaccurate over-coding or underreporting of some comorbid diagnoses. There is also an absence of important information related to patients' physical examination, medications, and laboratory results. We could not evaluate the time to coronary interventions. We could not consider the antibiotics used, delays in antibiotics, echocardiography, radiography, type of bacterial infection, and size of the vegetations. We could not evaluate whether any patient was admitted to a hospital without surgical facilities or to hospital without available ICU beds. We could not evaluate with certainty differences between surgical repair vs. replacement procedures. However, NEDS and the codes used in this study have been applied 
in multiple clinical studies [13] and can be considered a highly reliable database, and having the large cohort analyzed this minimizes the study limitation.

\section{CONCLUSIONS}

IE is related to several life-threatening complications and associated with high morbidity and mortality. Mortality is higher among patients with complicated IE. The prevalence of cardiogenic shock and DIC among IE patients was relatively less than that of septic shock; however, mortality was higher in these subgroups than for septic shock. Cardiovascular complications were the predominant complications from IE with an increasing trend of cardiogenic shock over the years 2016-2018. Surgical procedures performed among cardiogenic shock and septic shock had mortality benefits; however, overall rates were low. This would suggest improvement in rates of surgical procedures. Staphylococcus continues to complicate and worsen outcomes in IE, which would suggest more research to improve management of such infections.

\section{ACKNOWLEDGEMENTS}

Funding. No funding or sponsorship was received for this study or publication of this article.

Authorship. All named authors meet the International Committee of Medical Journal Editors (ICMJE) criteria for authorship for this article, take responsibility for the integrity of the work, and have given their approval for this version to be published.

Author Contributions. Tanveer Mir completed data analysis, study conception, writing the manuscript, and data collection. Waqas Qureshi helped in proofreading of statistical methods, idea generation, and proof reading of the manuscript. Mohammed Uddin and Neelambuj Regmi helped in the generation of graphics and tables and the review of the final manuscript. Imad Tleyjeh and Ghulam Saydain helped review the manuscript.

Disclosures. Waqas Quershi, Mohammed Uddin, Neelambuj Regmi, Imad Tleyjeh and Ghulam Saydain all having nothing to disclose. Tanveer Mir has an additional affiliation with Baptist Health System Montgomery Alabama included in the title page.

Compliance with Ethics Guidelines. The present analysis was exempt from institutional review board evaluation and was performed according to the ethical criteria set up by Healthcare Cost and Utilization Project (HCUP) [10].

Data Availability. Data are available in publicly available HCUP database [10].

Open Access. This article is licensed under a Creative Commons Attribution-Non Commercial 4.0 International License, which permits any non-commercial use, sharing, adaptation, distribution and reproduction in any medium or format, as long as you give appropriate credit to the original author(s) and the source, provide a link to the Creative Commons licence, and indicate if changes were made. The images or other third party material in this article are included in the article's Creative Commons licence, unless indicated otherwise in a credit line to the material. If material is not included in the article's Creative Commons licence and your intended use is not permitted by statutory regulation or exceeds the permitted use, you will need to obtain permission directly from the copyright holder. To view a copy of this licence, visit http:// creativecommons.org/licenses/by-nc/4.0/.

\section{REFERENCES}

1. Microbiology EbtESoC, Diseases I, Infection btISoCf, Cancer, Habib G, Hoen B, Tornos P, Thuny F, Prendergast B, Vilacosta I, Moreillon P, de Jesus Antunes M, Thilen U. Guidelines on the prevention, diagnosis, and treatment of infective 
endocarditis (new version 2009) The task force on the prevention, diagnosis, and treatment of infective endocarditis of the European Society of Cardiology (ESC). Eur Heart J. 2009;30:2369-413.

2. Chu VH, Cabell CH, Benjamin DK Jr, Kuniholm EF, Fowler VG Jr, Engemann J, Sexton DJ, Corey GR, Wang A. Early predictors of in-hospital death in infective endocarditis. Circulation. 2004;109: 1745-9.

3. Fedeli U, Schievano E, Buonfrate D, Pellizzer G, Spolaore P. Increasing incidence and mortality of infective endocarditis: a population-based study through a record-linkage system. BMC Infect Dis. 2011;11:1-7.

4. Murdoch DR, Corey GR, Hoen B, Miró JM, Fowler VG, Bayer AS, Karchmer AW, Olaison L, Pappas PA, Moreillon P. Clinical presentation, etiology, and outcome of infective endocarditis in the 21st century: the International Collaboration on Endocarditis-Prospective Cohort Study. Arch Intern Med. 2009;169:463-73.

5. Wallace S, Walton B, Kharbanda R, Hardy R, Wilson A, Swanton R. Mortality from infective endocarditis: clinical predictors of outcome. Heart. 2002;88: 53-60.

6. Pericàs JM, Hernández-Meneses M, Muñoz P, Martínez-Sellés $M$, de Alarcón A, Gutiérrez-Carretero E, Goenaga MA, Zarauza MJ, Falces C, RodríguezEsteban M. Characteristics and outcome of acute heart failure in infective endocarditis: focus on cardiogenic shock. Clin Infect Dis. 2021;73(5): 765-74.

7. Roth GA, Mensah GA, Johnson CO, Addolorato G, Ammirati E, Baddour LM, Barengo NC, Beaton AZ, Benjamin EJ, Benziger CP. Global burden of cardiovascular diseases and risk factors, 1990-2019: update from the GBD 2019 study. J Am Coll Cardiol. 2020;76:2982-3021.

8. Erbay AR, Erbay A, Canga A, Keskin G, Sen N, Atak R, Demir AD, Balbay Y, Duru E. Risk factors for inhospital mortality in infective endocarditis: five years' experience at a tertiary care hospital in Turkey. J Heart Valve Dis. 2010;19:216-24.

9. Olmos C, Vilacosta I, Fernandez C, Lopez J, Sarria C, Ferrera C, Revilla A, Silva J, Vivas D, Gonzalez I. Contemporary epidemiology and prognosis of septic shock in infective endocarditis. Eur Heart J. 2013;34:1999-2006.

10. Agency for Healthcare Research and Quality, Rockville, MD. 2018. 2014 introduction to the NEDS. Healthcare cost and utilization project (HCUP). https://hcup-us-ahrq-gov.proxy.lib.wayne.
edu/db/nation/neds/NEDS_Introduction_2014.jsp. Accessed 18 Dec 2019

11. Mir T, Qureshi WT, Uddin M, Shafi O, Sheikh M, Kakouros N. Non-ST elevation myocardial infarction and cardiac arrest: The United States Nationwide Emergency Department Sample. J Cardiol. 2021. https://doi.org/10.1016/j.jjcc.2021.08.016.

12. Mir T, Uddin M, Shafi O, Qureshi W, Kaur J, Zghouzi M, Lohia P, Soubani A, Burket M, Sheikh M, Saydain G. Thrombotic superior vena cava syndrome: a national emergency department database study. J Thromb Thrombolysis. 2021. https://doi. org/10.1007/s11239-021-02548-7.

13. Kadri AN, Wilner B, Hernandez AV, Nakhoul G, Chahine J, Griffin B, Pettersson G, Grimm R, Navia J, Gordon S. Geographic trends, patient characteristics, and outcomes of infective endocarditis associated with drug abuse in the United States from 2002 to 2016. J Am Heart Assoc. 2019;8:e012969.

14. Elixhauser A, Steiner C, Harris DR, Coffey RM. Comorbidity measures for use with administrative data. Med Care. 1998;36:8-27.

15. Moreillon P, Que YA. Infective endocarditis. Lancet. 2004;363:139149.

16. García-Cabrera E, Fernández-Hidalgo N, Almirante $\mathrm{B}$, Ivanova-Georgieva $\mathrm{R}$, Noureddine $\mathrm{M}$, Plata A, Lomas JM, Gálvez-Acebal J, Hidalgo-Tenorio C, Ruíz-Morales J. Neurological complications of infective endocarditis: risk factors, outcome, and impact of cardiac surgery: a multicenter observational study. Circulation. 2013;127:2272-84.

17. Bor DH, Woolhandler S, Nardin R, Brusch J, Himmelstein DU. Infective endocarditis in the US, 1998-2009: a nationwide study. PLoS ONE. 2013;8: e60033.

18. Fowler VG, Miro JM, Hoen B, Cabell CH, Abrutyn E, Rubinstein E, Corey GR, Spelman D, Bradley SF, Barsic B. Staphylococcus aureus endocarditis: a consequence of medical progress. JAMA. 2005;293: 3012-21.

19. Sunder S, Grammatico-Guillon L, Lemaignen A, Lacasse M, Gaborit C, Boutoille D, Tattevin P, Denes E, Guimard T, Dupont M, Fauchier L, Bernard L. Incidence, characteristics, and mortality of infective endocarditis in France in 2011. PLoS ONE. 2019; 14:e0223857.

20. Delahaye F, Alla F, Béguinot I, Bruneval P, DocoLecompte T, Lacassin F, Selton-Suty C, Vandenesch $\mathrm{F}$, Vernet $\mathrm{V}$, Hoen B. In-hospital mortality of infective endocarditis: prognostic factors and evolution over an 8-year period. Scand J Infect Dis. 2007;39:849-57. 
21. Kiefer T, Park L, Tribouilloy C, Cortes C, Casillo R, Chu V, Delahaye F, Durante-Mangoni E, Edathodu J, Falces C, Logar M, Miró JM, Naber C, Tripodi MF, Murdoch DR, Moreillon P, Utili R, Wang A, ICE-PCS Investigators $\mathrm{ft}$. Association between valvular surgery and mortality among patients with infective endocarditis complicated by heart failure. JAMA. 2011;306:2239-47.

22. Prendergast BD, Tornos P. Surgery for infective endocarditis: who and when? Circulation. 2010;121:1141-52.

23. Pant S, Patel Nileshkumar J, Deshmukh A, Golwala H, Patel N, Badheka A, Hirsch Glenn A, Mehta JL. Trends in infective endocarditis incidence, microbiology, and valve replacement in the United States from 2000 to 2011. J Am Coll Cardiol. 2015;65: 2070-6.

24. Scheggi V, Merilli I, Marcucci R, Del Pace S, Olivotto I, Zoppetti N, Ceschia N, Andrei V, Alterini B, Stefàno PL, Marchionni N. Predictors of mortality and adverse events in patients with infective endocarditis: a retrospective real world study in a surgical centre. BMC Cardiovasc Disord. 2021;21:28.

25. Thuny F, Disalvo G, Belliard O, Avierinos J-F, Pergola V, Rosenberg V, Casalta J-P, Gouvernet J, Derumeaux G, Iarussi D, Ambrosi P, Calabro R, Riberi A, Collart F, Metras D, Lepidi H, Raoult D, Harle J-R, Weiller P-J, Cohen A, Habib G. Risk of embolism and death in infective endocarditis: prognostic value of echocardiography. Circulation. 2005;112: 69-75.

26. Sobreiro DI, Sampaio RO, Siciliano RF, Brazil CVA, Branco CEDB, Lopes ASDSA, Tarasoutchi F, Strabelli TMV. Early diagnosis and treatment in infective endocarditis: challenges for a better prognosis. Arq Bras Cardiol. 2019;112:201-3.

27. Tornos P, Iung B, Permanyer-Miralda G, Baron G, Delahaye F, Gohlke-Bärwolf C, Butchart EG, Ravaud $\mathrm{P}$, Vahanian A. Infective endocarditis in Europe: lessons from the Euro heart survey. Heart. 2005;91: 571-5.

28. Roxas CJ, Weekes AJ. Acute myocardial infarction caused by coronary embolism from infective endocarditis. J Emerg Med. 2011;40:509-14.

29. Khan F, Khakoo R, Failinger C. Managing embolic myocardial infarction in infective endocarditis: current options. J Infect. 2005;51:e101-5.

30. Chen Z, Ng F, Nageh T. An unusual case of infective endocarditis presenting as acute myocardial infarction. Case Rep. 2009;2009:bcr1220081333.

31. Habib G, Erba PA, Iung B, Donal E, Cosyns B, Laroche C, Popescu BA, Prendergast B, Tornos P,
Sadeghpour A, Oliver L. Corrigendum to: clinical presentation, aetiology and outcome of infective endocarditis. Results of the ESC-EORP EURO-ENDO (European infective endocarditis) registry: a prospective cohort study. Eur Heart J. 2020;41: 2091.

32. Vikram HR, Buenconsejo J, Hasbun R, Quagliarello VJ. Impact of valve surgery on 6-month mortality in adults with complicated, left-sided native valve endocarditis: a propensity analysis. JAMA. 2003;290:3207-14.

33. Tutarel O, Alonso-Gonzalez R, Montanaro C, Schiff R, Uribarri A, Kempny A, Grübler MR, Uebing A, Swan L, Diller GP, Dimopoulos K, Gatzoulis MA. Infective endocarditis in adults with congenital heart disease remains a lethal disease. Heart. 2018;104:161-5.

34. Meine TJ, Nettles RE, Anderson DJ, Cabell CH, Corey GR, Sexton DJ, Wang A. Cardiac conduction abnormalities in endocarditis defined by the Duke criteria. Am Heart J. 2001;142:280-5.

35. Andersen LW, Holmberg MJ, Berg KM, Donnino MW, Granfeldt A. In-hospital cardiac arrest: a review. JAMA. 2019;321:1200-10.

36. Krajinovic V, Ivancic S, Gezman P, Barsic B. Association between cardiac surgery and mortality among patients with infective endocarditis complicated by sepsis and septic shock. Shock. 2018;49: 536-42.

37. Habib G. Embolic risk in subacute bacterial endocarditis: determinants and role of transesophageal echocardiography. Curr Cardiol Rep. 2003;5: 129-36.

38. Dickerman SA, Abrutyn E, Barsic B, Bouza E, Cecchi E, Moreno A, Doco-Lecompte T, Eisen DP, Fortes CQ, Fowler VG, Lerakis S, Miro JM, Pappas P, Peterson GE, Rubinstein E, Sexton DJ, Suter F, Tornos $\mathrm{P}$, Verhagen DW, Cabell $\mathrm{CH}$. The relationship between the initiation of antimicrobial therapy and the incidence of stroke in infective endocarditis: an analysis from the ICE Prospective Cohort Study (ICE-PCS). Am Heart J. 2007;154:1086-94.

39. Le V, Gill S. Serious complications after infective endocarditis. Dan Med Bull. 2010;57:A4192.

40. Morris NA, Matiello M, Lyons JL, Samuels MA. Neurologic complications in infective endocarditis: identification, management, and impact on cardiac surgery. Neurohospitalist. 2014;4:213-22.

41. Habib G, Lancellotti P, Antunes MJ, Bongiorni MG, Casalta J-P, Del Zotti F, Dulgheru R, El Khoury G, Erba PA, Iung B. 2015 ESC guidelines for the management of infective endocarditis: the task force for 
the management of infective endocarditis of the European Society of Cardiology (ESC) endorsed by: European Association for Cardio-Thoracic Surgery (EACTS), the European Association of Nuclear Medicine (EANM). Eur Heart J. 2015;36:3075-128.

42. Gagneux-Brunon A, Pouvaret A, Maillard N, Berthelot P, Lutz MF, Cazorla C, Tulane C, Fuzellier JF, Verhoeven PO, Frésard A, Duval X, Lucht F, Botelho-Nevers E. Acute kidney injury in infective endocarditis: a retrospective analysis. Med Mal Infect. 2019;49:527-33.

43. Tleyjeh IM, Steckelberg JM, Murad HS, Anavekar NS, Ghomrawi HM, Mirzoyev Z, Moustafa SE, Hoskin TL, Mandrekar JN, Wilson WR. Temporal trends in infective endocarditis: a population-based study in Olmsted County, Minnesota. JAMA. 2005;293: 3022-8.

44. DeSimone DC, Tleyjeh IM, Correa de Sa DD, Anavekar NS, Lahr BD, Sohail MR, Steckelberg JM, Wilson WR, Baddour LM. Incidence of infective endocarditis caused by viridans group streptococci before and after publication of the 2007 American Heart Association's endocarditis prevention guidelines. Circulation. 2012;126:60-4.

45. Pant S, Patel NJ, Deshmukh A, Golwala H, Patel N, Badheka A, Hirsch GA, Mehta JL. Trends in infective endocarditis incidence, microbiology, and valve replacement in the United States from 2000 to 2011. J Am Coll Cardiol. 2015;65:2070-6. 